\title{
A Model to Analyze the Design of the Toll Plaza
}

\author{
Ran Huang \\ Department of Economics \& Management, North China Electricity Power University, Baoding \\ 071000, China \\ 18331137016@163.com
}

\begin{abstract}
Keywords: design of barrier toll fan-in area, traffic congestion, cellular automaton, analytic hierarchy process.
\end{abstract}

\begin{abstract}
This paper focuses on the improvement of the toll plaza design, in order to solve the traffic congestion problem. In order to analyze the performance of the construction plan we define an evaluation index decided by the main issues in this model which are accident prevention, throughout and cost. We apply cellular-automaton approach and analytic hierarchy process to analyze this design. The shape, size, and merging pattern are determined by the fan-in area after the toll barrier.
\end{abstract}

\section{Introduction}

The development of the modern society has put forward higher request on transportation capacity. As the extension of toll roads, the design of the toll plaza has become a focus and difficulty. In this paper, we work on how to make maximum vehicles pass the area after the toll barrier safe and sound without spending too much money to construct the area.

We try to solve the problem by modeling the shape, size, and merging pattern of the area following the toll barrier in which vehicles fan in from B tollbooth egress lanes down to L lanes of traffic. In this paper, we try to design a model to determine the shape, size, and merging pattern of a basic fanin area after the toll barrier. The solution should take accident prevention, throughput and cost into consideration.

\section{Assumptions and Symbols}

\subsection{Assumption of the model}

Same type of tollbooths matches the same constant passing time.

The number of the open tollbooths in every single day is fixed.

Vehicles in this model have the same maximum velocity while their initial velocities (the speed before the vehicle access the toll plaza) are different.

When approaching the toll plaza, driver's separate pattern depends on their initial velocities and the traffic condition, seeking to achieve the shortest travel time.

Drivers do not cooperate. While the drivers are not directly competing against one other, they are affecting each other and are hence fierce indirect obstacles/opponents.

The moving pattern of all vehicles observes the traffic rules.

There are three types of cellular: vehicle cellular, blank cellular and banned cellular (which is closed to traffic).

The size of every single cellular is same. Its length, about 5 meters, equal to the length of the car plus the safety distance, and its width equals to the width of the traffic lane, which also equals to the width of the straight lane in Zone D.

It will take the vehicle 6 s to pay the tolls at the human-staffed tollbooth.

\subsection{Symbols}

We divided the whole area into six parts from Zone A to Zone F as shown in Figure 2.

Combined Zone B and Zone C, we defined it as the fan-out area in the toll plaza which is in front of the toll barrier. Besides, the area of the toll highway adjacent to the Zone B is defined as Zone A. 


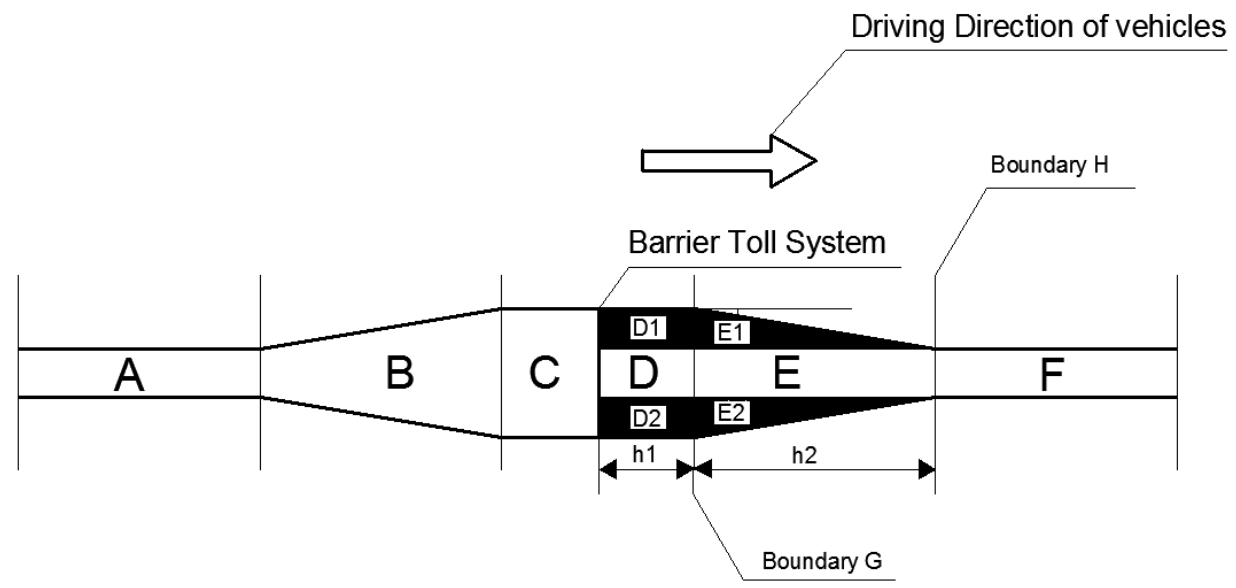

Figure 1 Sketch Map of the Toll Plaza

All the symbols used in the paper are listed as follow:

Table 1. Symbols Used In the Paper

\begin{tabular}{|c|c|c|}
\hline number & symbols & definition \\
\hline 1 & $\mathrm{~L}$ & The quantity of the traffic lanes in each direction \\
\hline 2 & B & The quantity of the tollbooths in each direction \\
\hline 3 & q & $\begin{array}{l}\text { The width of a traffic lanes (equal to the width of a straight lane in } \\
\text { Zone D) }\end{array}$ \\
\hline 4 & $\mathrm{i}$ & The serial number of the vehicle \\
\hline 5 & $v(i, t)$ & the velocity of the $i_{\text {th }}$ vehicle at time $t$ \\
\hline 6 & $x(i, t)$ & the position of the $i_{\text {th }}$ vehicle at time $t$ \\
\hline 7 & $d(i, t)$ & $\begin{array}{l}\text { The quantity of the blank cellular between } i_{\text {th }} \text { vehicle and the nearest } \\
\text { vehicle in front of it on the same lane at time } t\end{array}$ \\
\hline 8 & $v_{\max }$ & maximum velocity of the vehicle under certain circumstances \\
\hline 9 & $\mathrm{~V}_{\max }$ & Limitation maximum velocity of the road \\
\hline 10 & $\mathrm{v}_{\mathrm{b}}(\mathrm{i}, \mathrm{t})$ & $\begin{array}{l}\text { The velocity of the nearest vehicle which is on the neighboring lane } \\
\text { and behind the } i_{\text {th }} \text { vehicle at time } t\end{array}$ \\
\hline 11 & $\mathrm{~d}_{\mathrm{f}}(\mathrm{i}, \mathrm{t})$ & $\begin{array}{l}\text { The minimum quantity of the blank cellular between the } i_{t h} \text { vehicle } \\
\text { and the vehicle which is in the neighboring lane and in front of the } i_{t h} \\
\text { vehicle at time } t\end{array}$ \\
\hline 12 & $d_{b}(i, t)$ & $\begin{array}{l}\text { The minimum quantity of the blank cellular between the } i_{\text {th }} \text { vehicle } \\
\text { and the vehicle which is on the neighboring lane and behind the } i_{\text {th }} \\
\text { vehicle at time } t\end{array}$ \\
\hline 13 & $\mathrm{p}_{1}$ & The probability of lane changing in heavy traffic \\
\hline 14 & $\mathrm{p}_{2}$ & The probability of lane changing in light traffic \\
\hline 15 & $h_{1 j}$ & The length of $j_{\text {th }}$ straight lane in Zone $\mathrm{D}$ along the direction of the road \\
\hline 16 & $\mathrm{~h}_{2}$ & The length of Zone $\mathrm{E}$ along the direction of the road. \\
\hline 17 & $\theta$ & $\begin{array}{l}\text { The angle between the one side edge of Zone E and the direction of the } \\
\text { highway lane }\left(\theta<90^{\circ}\right)\end{array}$ \\
\hline 18 & $\mathrm{x}$ & $\tan \theta$ \\
\hline 19 & $\mathrm{Y}$ & The number of accidents happened per year \\
\hline 20 & S & $\begin{array}{l}\text { The surface area of the extra road constructed because of the build of } \\
\left.\text { the toll system.(The surface area of the shadowed Zone } D_{1}, D_{2}, E_{1}, E_{2}\right)\end{array}$ \\
\hline 21 & $\mathrm{~N}_{\mathrm{j}}$ & $\begin{array}{l}\text { The number of vehicles per hour passing the point where the end of the } \\
\text { plaza joins the L outgoing traffic lanes under different traffic condition }\end{array}$ \\
\hline 22 & $\mathrm{M}$ & The construction cost of per unit area \\
\hline 23 & $\lambda$ & The accident prevention rate \\
\hline
\end{tabular}




\section{Model}

\subsection{The foundation of the model}

The model will be affected by three main factors: throughout (number of the vehicles per hour passing the point where the end of the plaza joins the $L$ outgoing lanes), accident prevention and the cost (which is related to the surface area). First, we discuss these factors respectively. Than define a comprehensive evaluation index to analyze the performance of every plan.

3.1.1 Throughout

We applied cellular-automaton approach to simulate the vehicle's moving pattern. According to the probability of vehicle occurrence in every lane, we divided the traffic condition into three types, which are heavy traffic, normal traffic and light traffic. Then we set the maximum velocity of the vehicles as 3 and the acceleration during accelerating time as 1, while the acceleration during decelerating time is unsettled. The initial velocity of the vehicles is chosen randomly from 1 to 3 .

Specific driving rules are as followed:

Acceleration rule:

If $\mathrm{v}(\mathrm{i}, \mathrm{t}) \leq \mathrm{v}_{\max }$

There will be $\mathrm{v}(\mathrm{i}, \mathrm{t}+1)=\min \left[\mathrm{v}_{\max }, v(i, t)+1\right]$

Meanwhile $\mathrm{v}_{\max } \leq V_{\max }$

Deceleration rule:

$\mathrm{v}(\mathrm{i}, \mathrm{t}+1) \leq \min \left[\frac{\mathrm{d}(\mathrm{i}, \mathrm{t})}{1}, \mathrm{v}(\mathrm{i}, \mathrm{t})\right]$,

Random deceleration rule:

Uncertain factors lead to the probability of the deceleration of the vehicle is $\mathrm{P}$.

$0 \leq \mathrm{v}(\mathrm{i}, \mathrm{t}+1) \leq \mathrm{v}(\mathrm{i}, \mathrm{t})-1$,

Moving rule:

$$
x(i, t+1) \leq x(i, t)+v(i, t+1) \times 1,
$$

Lane changing rule:

When traffic congestion happened on one lane, the vehicle could change its lane to the unblocked lane, if all the following criteria are met:

$$
\left\{\begin{array}{c}
\frac{\mathrm{d}(\mathrm{i}, \mathrm{t})}{1}<\min \left(v_{\text {max }}, v(i, t)+1\right) \\
d_{f}(i, t)>d(i, t) \\
d_{b}(i, t)>1+\min \left(v_{b}(i, t)+1, v_{\max }\right)-\min \left(v(i, t)+1, v_{\max }\right) \\
\text { rand }()<\mathrm{p}_{1}(\text { rand }(\text { ) is a random number between } 0 \text { to } 1)
\end{array}\right.
$$

Meanwhile, the unblocked lane should also meet all the following criteria:

$$
\left\{\begin{aligned}
& \frac{\mathrm{d}(\mathrm{i}, \mathrm{t})}{1}> \max \left(v_{\max }, v(i, t)+1\right) \\
& d_{f}(i, t)>d(i, t) \\
& d_{b}(i, t)>v_{\max } \\
& \text { rand }(\quad)<\mathrm{p}_{2}(\text { rand }(\quad) \text { is a random number between } 0 \text { to } 1)
\end{aligned}\right.
$$

And $\mathrm{p} 1 \gg \mathrm{p} 2$

According to cellular-automaton approach ${ }^{[4]}$, we can calculate the throughput of different traffic conditions (heavy traffic, normal traffic and light traffic) given the values of $B, L, h_{1}, h_{2}$. The values of $B$ and $L$ can be determined by analyzing and experience. Thus, we discuss how the values of $h_{1}$ and $\mathrm{h}_{2}$ could affect the throughout.

The weighted average throughout can be repent as follow:

$$
\mathrm{N}=\sum \mathrm{N}_{j} \mathrm{t}_{j}
$$

Where:

$\mathrm{N}_{1}$ is throughout under heavy traffic condition

$\mathrm{N}_{2}$ is throughout under normal traffic condition

$\mathrm{N}_{3}$ is throughout under light traffic condition

$t_{1}$ is the proportion of heavy traffic time to the whole time.

$t_{2}$ is the proportion of normal traffic time to the whole time. 
$t_{3}$ is the proportion of light traffic time to the whole time.

Given

$$
\mathrm{B}=8, \mathrm{~L}=3
$$

Applying cellular-automaton approach to simulate the vehicles moving in half an hour of the heavy traffic time, the results are shown below:

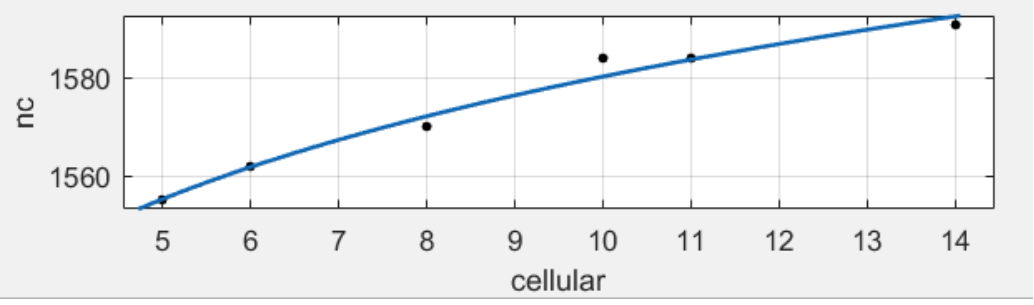

Where:

Figure 2. The relationship between $\boldsymbol{n c}$ and the number of cellular

cellular is the number of cellular, and the length of it is 5 meters.

$\mathrm{nc}$ is the half of $\mathrm{N}$

After regression analysis, the specific regression model between the half hour throughout (nc) and cellular is showed as follow:

$\mathrm{nc}=1498$ cellular $^{0.02309}$

$\mathrm{R}^{2}=0.9791$

The model is fine for its high relevance.

Increase the vehicle density of Zone A, we can get the figure:

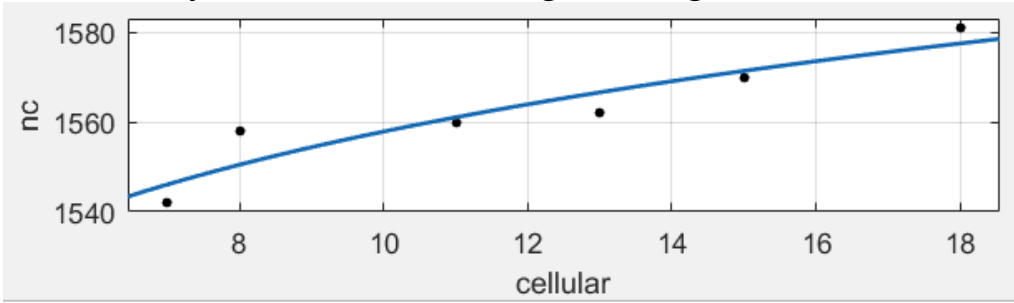

Figure 3 the relationship between $\boldsymbol{n c}$ and the number of cellular on heavy traffic condition

And the regression model:

$\mathrm{nc}=1483$ cellular $^{0.02229}$

$\mathrm{R}^{2}=0.8903$

Given $B=8, L=3$, during the heavy traffic time, throughout can be calculated in the equation shown below:

$$
\mathrm{N}_{1}=2 * \mathrm{nc}=2980\left(\frac{\mathrm{h}_{1}+\mathrm{h}_{2}}{5}\right)^{0.025}
$$

Given

$\mathrm{B}=12, \mathrm{~L}=4$

Simulating the vehicles moving in half an hour of the heavy traffic time, the curve and model are shown below:

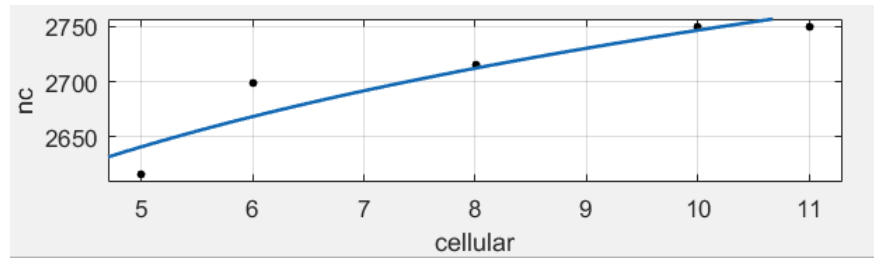

Figure 4. The relationship between $\boldsymbol{n c}$ and the number of cellular based in different values of $\mathbf{B}$ and

$\mathrm{nc}=2412$ cellular 0.05643

$\mathbf{L}$

$\mathrm{R}^{2}=0.8874$

In summary, the universal model between maximum $\mathrm{N}_{1}$ and $\mathrm{h}_{1}, \mathrm{~h}_{2}$ is presented as follow:

$\mathrm{N}_{1}=\mathrm{a}\left(\frac{\mathrm{h}_{1}+\mathrm{h}_{2}}{5}\right)^{\mathrm{b}}$

Where: 
The values of $\mathrm{a}, \mathrm{b}$ depend on $\mathrm{B}$ and $\mathrm{L}$.

Taking statistic data from one toll highway in New Jersey for several days, we were able to get the scatter diagram as followed:

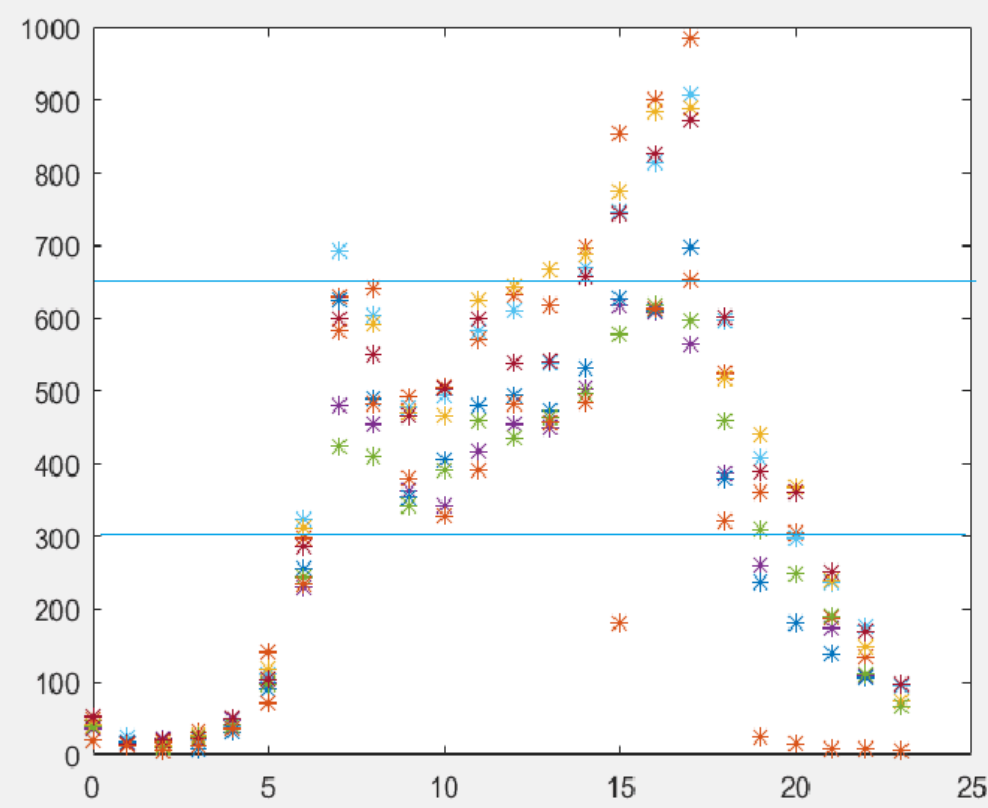

Figure 5. The scatter diagram on one-day-throughout of one certain toll highway in New Jersey According to the scatter diagram, we determine:

$\mathrm{t}_{1}=0.12$

$\mathrm{t}_{2}=0.42$

$\mathrm{t}_{3}=0.46$

3.1.2 Accident prevention rate

Two main factors contribute to accident. The first one is that the safe distance is too short. We have already taken this factor into consideration when design the length of the cellular. The second one is the angle between the side edge of Zone $\mathrm{E}$ and the direction of the highway lane, which is defined as $\theta$. With the decrease of the value of $\mathrm{x}$, which equals to $\tan \theta$, the driver would be safer. Otherwise, the driver may have the sense of drift, which may cause drivers and passengers feeling uncomfortable and endanger security of driving ${ }^{[5]}$.

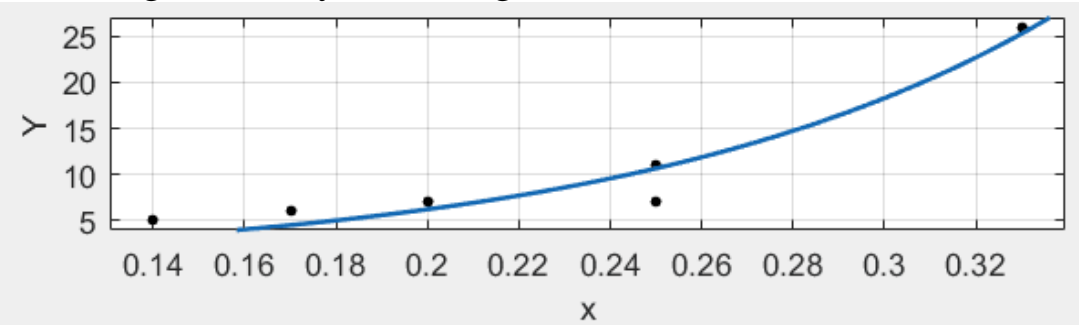

Figure 6 the relationship between the number of accidents happened per year $(\mathbf{Y})$ and $\mathrm{x}$

After regression analysis, the specific regression model between the number of accidents happened per year $(\mathrm{Y})$ and $\mathrm{x}$ is showed as follow:

$\mathrm{Y}=0.07133 \mathrm{e}^{10.81 x}$

The correlation coefficient of the model is

$\mathrm{R}^{2}=0.9367$

Thus, the model between $\mathrm{x}$ and $\mathrm{Y}$ is fine because of its high relevance. According to the regression curve and model, $\mathrm{Y}$ has positive correlation with $\mathrm{x}$. Excessive $\mathrm{x}$ could lead to the length of Zone D inadequate, in another word, the visual range to judge the vehicle security is not met the standard. It cannot meet the safety requirements of accelerating and lane changing. Thus, the accident may happen. 
The accident prevention rate $\lambda$ has negative correlation with Y. In order to simplify the calculation, we define:

$$
\lambda=\frac{1}{\mathrm{Y}}
$$

$\mathrm{x}$ is related to $\mathrm{h}_{2}, \mathrm{~B}, \mathrm{~L}$ and $\mathrm{q}$ and can be calculated in the equation shown below: $\mathrm{X}=\frac{(B-L) q}{2 h_{2}}$

Finally, we can get the equation as followed:

$$
\lambda=\frac{1}{2.206 \mathrm{e}^{6.867\left(\frac{\mathrm{B}-\mathrm{L}) \mathrm{q}}{2 \mathrm{~h}_{2}}\right)}}
$$

\subsubsection{Construction cost}

Land and road construction are expensive, thus, we should take cost into consideration. Total cost $\mathrm{W}$ can be presented as:

$\mathrm{W}=\mathrm{SM}$

$S$ is the surface area of the extra road constructed because of the build of the toll system, in another word ,it is the surface area of the shadowed Zone $\mathrm{D}_{1}, \mathrm{D}_{2}, \mathrm{E}_{1}, \mathrm{E}_{2}$. It can be calculated in the equation shown below:

$$
\mathrm{S}=\left(\mathrm{H}_{1}+\frac{\mathrm{H}_{2}}{2}\right)(B-\mathrm{L}) \mathrm{q}
$$

Where:

$\mathrm{M}$ is the construction cost of per unit area.

Finally, we can get the equation as followed:

$\mathrm{W}=\left(\mathrm{H}_{1}+\frac{\mathrm{H}_{2}}{2}\right)(\mathrm{B}-\mathrm{L}) \mathrm{qM}$

3.1.4 Comprehensive evaluation index

In order to analyze the performance of the new designed fan-in area, we defined an evaluation index I, which is presented as follow:

$$
\mathrm{I}=k_{1} \frac{N_{\max }-N\left(h_{1}, h_{2}\right)}{N_{\max }-N_{\min }}+k_{2} \frac{\lambda_{\max }-\lambda\left(h_{1}, h_{2}\right)}{\lambda_{\max }-\lambda_{\min }}+k_{3} \frac{W\left(h_{1}, h_{2}\right)-\mathrm{W}_{\min }}{\mathrm{W}_{\max }-\mathrm{W}_{\min }}
$$

Where:

$\mathrm{N}\left(\mathrm{h}_{1}, \mathrm{~h}_{2}\right), \lambda\left(\mathrm{h}_{1}, \mathrm{~h}_{2}\right)$ and $\mathrm{W}\left(\mathrm{h}_{1}, \mathrm{~h}_{2}\right)$ indicate the throughout, accident prevention rate and the total cost respectively when the value of $h_{1}$ and $h_{2}$ are given.

$\mathrm{N}_{\max }, \lambda_{\max }$ and $\mathrm{W}_{\max },\left(\mathrm{N}_{\min }, \lambda_{\min }\right.$ and $\left.\mathrm{W}_{\min }\right)$ are the maximum (or the minimum) value of throughout, accident prevention rate and the total cost when the certain ranges of $h_{1}$ and $h_{2}$ are given.

$\mathrm{k}_{1}$ is the weight of throughout.

$\mathrm{k}_{2}$ is the weight of accident prevention.

$\mathrm{k}_{3}$ is the weight of cost.

The specific values of $\mathrm{k}_{1}, \mathrm{k}_{2}, \mathrm{k}_{3}$ is determined by the certain circumstance. The smaller $\mathrm{I}$ is, the better performance of the model has.

\subsection{Analysis of the results}

Given the condition as followed:

$$
\begin{aligned}
& \mathrm{B}=8, \mathrm{~L}=3, \mathrm{q}=3 \mathrm{~m}, \mathrm{M}=8000 \text { dollar } / \mathrm{m}^{2} \\
& \mathrm{k}_{1}=1.4, \mathrm{k}_{2}=1.6, \mathrm{k}_{13}=2.8
\end{aligned}
$$

Applying Matlab make the three-dimension figure of $h_{1}$ (presented as $x$ in Fig) and $h_{2}$ (presented as $y$ in Fig). The the certain ranges of $h_{1}$ and $h_{2}$ are determined by experience. 


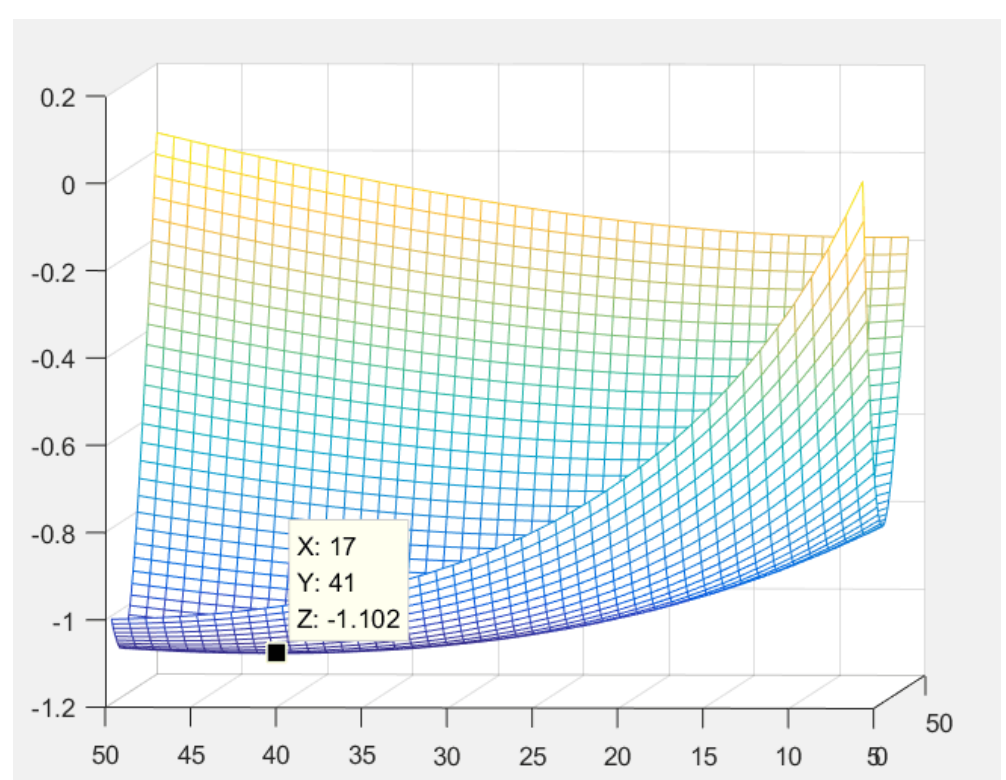

Figure 7 the three-dimension figure of $\mathbf{I}, \mathbf{h}_{\mathbf{1}}$ (presented as $\mathrm{x}$ in Fig) and $\mathbf{h}_{\mathbf{2}}$ (presented as $\mathrm{y}$ in

According to the Fig, when $h_{1}=17 \mathrm{~m}$ and $h_{2}=41 \mathrm{~m}$, we can obtain a minimum value of $E$, in another word, the optimal values of $h_{1}$ and $h_{2}$ are $17 \mathrm{~m}$ and $41 \mathrm{~m}$.

\section{Conclusion}

We applied cellular-automaton approach to simulate the vehicle's moving pattern in order to discuss how $h_{1}$ and $h_{2}$ affect the throughout; taking data from varied sources, we were able to figure out how $h_{1}$ and $h_{2}$ affect the accident prevention rate and the cost.

Using analytic hierarchy process, we defined an evaluation index to analyze the performance of the new designed fan-in area, this index combined with the throughout, accident prevention rate as well as the cost.

According to the model above, when given the values of B, L, M, q, we can get the values of $h_{1}, h_{2}$. Based on the values of $h_{1}$ and $h_{2}$, the shape and size of the fan -in area is determined. The values of $h_{1}$ and $h_{2}$ set the area where the vehicles should go straight and where the vehicles can merge, so that the merging pattern of the car also depends on them. Solving the model we can get the optimal values of $h_{1}$ and $h_{2}$ given the values of $B, L, M, q$. In accordance with the strategy above to build the toll plaza, the throughout, accident prevention rate as well as the cost will meet the design requirements as far as possible.

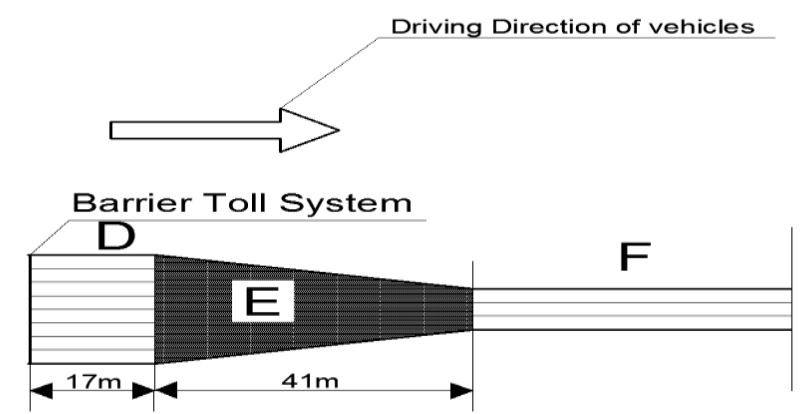

Figure 8 sketch map of the optimal solution

\section{References}

[1]https://en.wikipedia.org/wiki/Toll_road

[2] Wu xiaowu. The search the on the transportation security of the highway toll plaza [D].Chang'An University.

[3] Lvwen Zhou. Matlab code for MCM 2005 problem B. 